\title{
Serial discrimination reversal learning: Effects of scopolamine
}

\author{
GEORGE W. HANDLEY and WILLIAM H. CALHOUN \\ University of Tennessee, Knoxville, Tennessee 37916
}

\begin{abstract}
A repeated acquisition procedure (baseline serial discrimination reversals, SDR) was used to test the effects of scopolamine hydrobromide in 12 male rats. The rats were trained in a tone/light SDR procedure until performance on successive reversals had stabilized. At that point, three drug doses were tested for effects upon learning, as measured by the repeated acquisition procedure. It was noted that, in general, scopolamine did not interfere with learning in this paradigm; instead, scopolamine interfered with the ability of the animals to discriminate between the various stimuli present in this situation. Thus, the conclusion was that the drug does disrupt performance in baseline SDR, but that the nature of the disruption is not related to the association process.
\end{abstract}

Scopolamine is purported to produce amnesia in humans. For example, it was reported that scopolamine, when used with other drugs during twilight sleep, produced amnesia for the delivery (Goodman \& Gilman, 1955). Longo (1966) reviewed the literature on the effects of atropine and related compounds, which included scopolamine, and wrote: "Scopolamine causes definite psychic sedation in most cases and at times actual amnesia" (Longo, 1966, p. 978). The beliefs that scopolamine is an amnesic agent and that cholinergic mechanisms are involved in learning and memory (e.g., Carlton, 1963) have led many researchers to study the effects of scopolamine on animals in a variety of learning situations (cf. Carlton \& Markiewicz, 1971).

Any final answer is far away. There are conflicting reports, with scopolamine disrupting some types of learning, such as passive avoidance (Bohdanecky \& Jarvik, 1967; Calhoun \& Smith, 1968), and enhancing or not affecting other types of learning, such as active avoidance (Calhoun, Smith, \& Bauer, 1970; Oliverio, 1967). Furthermore, recent research provides alternative interpretations. Heise, Conner, and Martin (1976) reported results using a variable intertrial interval paradigm, and they concluded that scopolamine did not impair memory in rats. Warburton and Brown (1976), using a signal detection paradigm with rats, reported that scopolamine's principal action was to disrupt discrimination.

In summary, the most recent evidence suggests that scopolamine is not an amnesic agent per se, but affects learning through interference with the discrimination process. Yet, any final conclusion would be premature. The long-standing problem of the separation of learning from performance prevents one from isolating the effects of the drug. One way to avoid this problem may 45804 . be to use a precise and rigorous behavioral technique to define the learning process. One procedure proposed by several authors (Boren \& Devine, 1968; Calhoun \& Jones, 1974a, 1974b; Thompson, 1970, 1973) is a repeated acquisition procedure to permit development of a baseline for acquisition. It is believed that a repeated acquisition procedure provides the rigor that has been so well applied through operant psychology to study numerous behavioral phenomena. There is some question whether acquisition in a repeated acquisition procedure is identical to acquisition in the original state. Similarities between the process of the two conditions seem to be sufficiently strong to warrant extrapolation from the repeated acquisition procedure to normal acquisition. In this study, a special kind of repeated acquisition method, serial discrimination reversal (SDR), was tested for effects of scopolamine.

\section{METHOD}

\begin{abstract}
Subjects
The subjects were 12 male rats of the Sprague-Dawley strain purchased from ARS Sprague-Dawley suppliers. Subjects were between 110 and 130 days of age at the beginning of the experiment and weighed between 375 and $410 \mathrm{~g}$. Food was available throughout the course of the experiment.
\end{abstract}

\begin{abstract}
Apparatus
The apparatus consisted of two single-lever operant chambers (Lafayette, Model A-630). Each chamber was equipped with a liquid dispenser and a red houselight located on the ceiling of the chamber. The chambers were placed in sound-attenuated cubicles ventilated by exhaust fans. The stimuli were presented and responses recorded by electromechanical equipment located outside the cubicles. The stimulus periods were signaled by either a light or tone. The light was a $28-\mathrm{V}$ pilot lamp located $7 \mathrm{~cm}$ above the bar. The tone was generated by a $2,900-\mathrm{Hz}$ Sonalert electric signal (Mallory, Model SC-628). The intensity was attenuated by a $27-\mathrm{kohm}$ resistor to a nonnoxious level.
\end{abstract}


Procedure

The subjects were adapted to a 23-h water deprivation schedule and shaped to barpress for reinforcement (.1 cc of $9 \%$ sucrose solution) on a continuous reinforcement schedule. A discrete trial operant procedure, as described by Kulig and Calhoun (1972) was then employed. A tone or light was presented for $6 \mathrm{sec}$, with an intertrial interval (ITI) of $10 \mathrm{sec}$ intervening between the stimulus presentations. The sequence of stimulus presentations was predetermined by a Gellerman series. A response during either stimulus presentation resulted in reinforcement. Responding during the ITI was suppressed by the resetting of the interval timer. The subjects were trained in the discrete trial situation for 150 trials per day for 5 days. The SDR procedure was then introduced. On each daily training session of 300 trials each, the reward value of the trial stimuli was reversed. The subjects were trained in this procedure for 39 sessions prior to the introduction of drug treatments to produce relatively stable performance. The subjects were divided into three groups of four subjects each. A Latin square design was employed to randomize the order in which the drug treatments (consisting of an IP injection of $.125, .25$, or $.50 \mathrm{mg} / \mathrm{kg}$ of scopolamine hydrobromide) were administered to the groups. Drug treatments were administered 20 min prior to every third daily training session, starting with the 40 th session. The frequency per session of S+ responses, errors, and intertrial responses was recorded.

\section{RESULTS AND DISCUSSION}

A single measure of efficiency during one SDR session is the discrimination ratio (DR) (number of errors $\div$ number of responses) (Handley, 1972). For this study the DR was determined for the predrug (before), drug (during), and postdrug (after) days for all doses (see Figure 1). There was no significant effect for the .125 - and $.25-\mathrm{mg} / \mathrm{kg}$ doses. By contrast, the .50 dose significantly increased the DR (during vs. before, $p=.04$, two-tailed Wilcoxon test).

Analysis of the SDR measures showed that the effect on the DR resulted from a combination of a decrease in St responses and an increase in errors (see Table 1). Taken alone, this effect might suggest that scopolamine interfered with learning. However, further examination of the data showed that the .50 dose also increased
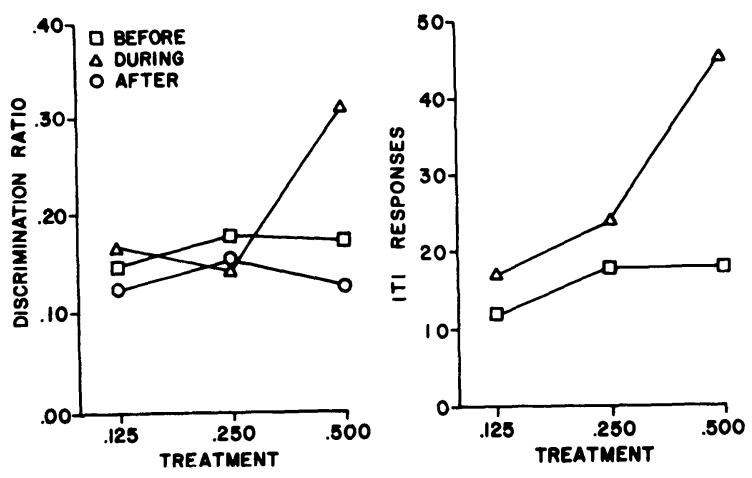

Figure 1. DR and ITI responses as related to dosage of scopolamine hydrobromide.
Table 1

SDR Measures as Related to Drug Dose

\begin{tabular}{|c|c|c|c|c|c|c|}
\hline \multirow{3}{*}{$\begin{array}{c}\text { Dose } \\
(\mathrm{mg} / \mathrm{kg})\end{array}$} & \multicolumn{6}{|c|}{ SDR Measures } \\
\hline & \multicolumn{2}{|c|}{$S+$} & \multicolumn{2}{|c|}{ S- } & \multicolumn{2}{|c|}{ ITI } \\
\hline & Mean & $\mathrm{SD}$ & Mean & SD & Mean & $\mathrm{SD}$ \\
\hline .125 & 124.25 & 22.76 & 20.00 & 7.67 & 17.25 & 7.42 \\
\hline .250 & 131.50 & 11.01 & 18.25 & 11.31 & 24.12 & 8.49 \\
\hline .500 & 100.50 & 27.34 & 27.50 & 16.50 & 44.88 & 25.46 \\
\hline
\end{tabular}

intertrial responding (during vs. before, $\mathrm{p}<.01$, twotailed Wilcoxon test). Thus, the high dose appeared to disrupt discrimination. When the rats were drugged with $.50 \mathrm{mg} / \mathrm{kg}$ of the drug, they responded as often as with the lower doses, because the sum of St responses, errors, and ITI responses was about the same for all dose levels (as indicated in Table 1), but they discriminated more poorly, as they responded less during $\mathrm{S}+$ and more during the ITI and $\mathrm{S}-$ intervals.

In conclusion, low doses of scopolamine did not affect learning as measured in a repeated acquisition procedure. A relatively high dose of the drug, however, appeared to disrupt discrimination. This conclusion agrees with those of other recent research (Heise et al., 1976; Warburton \& Brown, 1976).

\section{REFERENCES}

Boren, J. J., \& DEvine, D. D. The repeated acquisitions of behavioral chains. Journal of the Experimental Analysis of Bchavior, 1968, 11. 651-660.

BOHDANECKY, Z., \& JARVIK, M. E. Impairment of one-trial passive avoidance learning in mice by scopolamine, scopolamine methylbromide, and physostigmine. International Journal of Neuropharmacology. 1967, 6. 217-222.

Calhoun, W. H.. \& Jones, E. A. Repeated acquisitions for studying drug effects on acquisition. Federation Proceedings, 1974. 33. 550 (abstract). (a)

Catholin. W. H., \& Jones, E. A. Methamphetamine's effect on repeated acquisitions with serial discrimination reversals. Psichopharmacologia (Berlin), 1974, 39. 303-308. (b)

Calmoun. W. H. \& Smith, A. A. Effects of scopomaline on acquisition of passive avoidance. Psychopharmacologia (Berlin). 1968, 13, 201-209.

Calhoun, W. H., Smith, A. A., \& Bauer, R. Scopolamine's effect on passive avoidance. Psychonomic Science, 1970. 21. $165-166$.

Carlton, P. L. Cholinergic mechanisms in the control of behavior by the brain. Psychological Revien, 1963, 70, 19-39.

Carlton, P. L. \& MARKIEWicz, B. Behavioral effects of atropine and scopolamine. In E. Furchtgott (Ed.). Pharmacological and biophysical agents and behavior. New York: Academic Press. 1971.

Goodman, L. S.. \& Gilman, A. The pharmacological basis of therupe'utics (2nd. ed.). New York: Macmillan. 1955.

Handery, G. W. The effects of methyphenidate [Ritalin] upon performance in the successive discrimination reversal situation. Unpublished doctoral dissertation. University of Tennessee. Knoxville. 1972.

Heise. G. A., Conner. R., \& Martin, R. A. Effects of scopolamine on variable intertrial interval spatial alternation and memory in the rat. Psichopharmacologi, 1976, 49, 131-137. 
Kulig. B. M.. \& Calhoun. W. H. Enhancement of successive discrinination reversal learning by methamphetamine. Psychophurmacologia (Berlin), 1972, 27, 233-240.

LoNGo. V. G. Behavioral and electroencephalographic effects of atropine and related compounds. Pharmacological Review, 1966. 18. $965-996$.

Oliverio. A. Contrasting effects of scopolamine on mice trained simultaneously with two different schedules of avoidance conditioning. Psychopharmacologia (Berlin), 1967, 11, 39-51.

Thompson. D. M. Repeated acquisitions as a behavioral baseline. Psychonomic Science, 1970, 21, 150-157.
Thompson. D. M. Repeated acquisition as a behavioral baseline for studying drug effects. Journal of Pharmacology and Experimental Therapeutics, 1973. 184. 506-514.

Warburton. D. M.. \& Brown, K. Effects of scopolamine on a double stimulus discrimination. Neuropharmacology, 1976, 15, 659-663. 